Article

\title{
Ductal Carcinoma In Situ Underestimation of Microcalcifications Only by Stereotactic Vacuum-Assisted Breast Biopsy: A New Predictor of Specimens without Microcalcifications
}

\author{
Yun-Chung Cheung ${ }^{1}$, Shin-Cheh Chen ${ }^{2}$, Shir-Hwa Ueng ${ }^{3}$ and Chi-Chang $\mathrm{Yu}^{2, *}$ (1) \\ 1 Department of Diagnostic Radiology, Chang Gung Memorial Hospital, Medical College of Chang \\ Gung University, Taoyuan 333, Taiwan; alex2143@cgmh.org.tw \\ 2 Department of Surgery, Chang Gung Memorial Hospital, Medical College of Chang Gung University, \\ Taoyuan 333, Taiwan; chensc@cgmh.org.tw \\ 3 Department of Pathology, Chang Gung Memorial Hospital, Medical College of Chang Gung University, \\ Taoyuan 333, Taiwan; susie.ueng@gmail.com \\ * Correspondence: kenneth0609@cgmh.org.tw; Tel.: +886-27-135-211
}

Received: 30 August 2020; Accepted: 15 September 2020; Published: 17 September 2020

check for updates

\begin{abstract}
The mammographic appearance of ductal carcinoma in situ (DCIS) is mostly observed as microcalcifications. Although stereotactic vacuum-assisted breast biopsy (VABB) is a reliable alternative to surgical biopsy for suspicious microcalcifications, underestimation of VABB-proven DCIS is inevitable in clinical practice. We therefore retrospectively analyzed the variables in the prediction of DCIS underestimation manifesting as microcalcifications only proved by stereotactic VABB. In 1147 consecutive VABB on microcalcification-only lesions from 2010 to 2016, patients diagnosed with DCIS were selected to evaluate the underestimation rate. The analyzed variables included clinical characteristics, mammographic features, VABB procedure, and biomarkers. Univariate and multivariate analyses were used, and a $p$ value $<0.05$ was considered statistically significant. Of the 131 VABB-proven DCIS, 108 cases were diagnosed with DCIS and 23 were upgraded to invasive ductal carcinoma (IDC) after subsequent surgery. The small extent of microcalcification, grouped microcalcifications distribution, nearly complete microcalcification removal, and non-calcified specimens without DCIS were low for DCIS underestimation. Among them, the results of non-calcified specimens with or without DICS were the only statistically significant variables by multivariate logistic regression. These results indicate that the histology of non-calcified specimens was highly predictive of DCIS underestimation. Specimens without DCIS had a low upgrade rate to IDC.
\end{abstract}

Keywords: breast microcalcifications; ductal carcinoma in situ; underestimation; vacuum-assisted breast biopsy

\section{Introduction}

Stereotactic vacuum-assisted breast biopsy (VABB) is the standard for the diagnosis of suspicious malignant breast microcalcifications. Meanwhile, there are no advanced imaging diagnostic modalities that can replace the histological diagnosis. This mammography-guided biopsy can be used to diagnose asymptomatic noninvasive or invasive cancers manifesting only with microcalcifications that have been proven to efficiently reduce the mortality of breast cancer [1].

Minimally invasive percutaneous core needle biopsy is a cost-effective and reliable alternative to surgical biopsy for tissue sampling of suspicious breast lesions, regardless of the screening or clinical diagnostic context [2]. Although VABB is a promising technique for obtaining abundant 
tissues for microscopic evaluation [3,4], the underestimation of atypia lesions (including atypical ductal hyperplasia and flat epithelial atypia) to ductal carcinoma in situ (DCIS) has been reported to range from $0 \%$ to $21 \%$ for flat epithelial atypia [5-7] and $10 \%$ to $29 \%$ for atypical ductal hyperplasia [8-10]. To avoid delayed treatment of early cancers, management with subsequent surgical biopsy should be recommended as guidance [11-13], and this has been universally accepted.

In other aspects of clinical consideration, this study aimed to investigate another issue of DCIS underestimation. A meta-analysis of 7350 cases of DCIS including masses or microcalcifications from 52 studies reported a $30.3 \%$ underestimation rate of invasive carcinoma for 14-gauge core needle biopsy and $18.9 \%$ for 11-gauge VABB [14]. Although the priority of surgical treatment is universal for noninvasive or invasive breast cancer, the performance of sentinel lymph node biopsy is different between DCIS and invasive ductal cancers (IDCs). According to the guidelines on sentinel lymph node performance, sentinel lymph node biopsy should be essential for IDC, but not for DCIS [15]. To provide an assessment to predict the underestimation of biopsied DCIS, we retrospectively reviewed the results of VABB in cases with breast microcalcifications only and analyzed the variables from patient characteristics, mammographic features, VABB procedural relationships, and biopsy biomarkers among the VABB-proven DCIS. Knowingly, the assessment of specimens without calcification was first evaluated.

\section{Materials and Methods}

\subsection{Patients}

This retrospective study was approved by the Institutional Review Board of our hospital (Chang Gung Memorial Hospital, Linkou Medical Center). All cases were clinically based, and the requirement for informed consent was waived. From the data bank of stereotactic VABB on breast microcalcifications between January 2010 and December 2016, 1147 consecutive cases were reviewed. To analyze the parameters in predicting the underestimation of biopsied DCIS, the following inclusion criteria were used: (1) All cases had been diagnosed with DCIS by stereotactic VABB and subsequently received surgery within 2 weeks; (2) all the biopsied targets manifested as microcalcifications only (without associated masses) on mammograms; (3) none of the patients had any palpable mass or associated sonographic mass after evaluation by breast surgeons; (4) all biopsies were performed with VABB, either with 7-gauge or 10-gauge biopsy needles; (5) all procedures had documented successful calcification retrieval by specimen mammograms; and (6) all cases had individual diagnoses on the specimens with and without microcalcifications.

\subsection{Stereotactic Breast Biopsy on Microcalcifications}

All patients signed an agreement for stereotactic guided breast biopsy according to the regulations of our hospital. Stereotactic biopsies were performed by radiologists with at least 10 years of experience in mammographic interpretation and stereotactic guided core needle breast biopsy using digital mammographic devices (Lorad, Selenia, Bedford, MA, USA) with an add-on stereotactic biopsy unit (Lorad, Danbury, NY, USA). With the paired mammographic projections at $+15^{\circ}$ and $-15^{\circ}$, the coordinates ( $x, y$, and $\mathrm{z}$ axis) of the selected target could be obtained by computed calculation. Under local anesthesia with $2 \%$ lidocaine $(5-10 \mathrm{~mL})$ injection over puncture sites, the biopsies were performed with vacuum-assisted biopsy devices (Vacora or Encor; Bard, Irvine, CA, USA). Before termination of the procedure, radiography of the obtained specimens was routinely performed using a mammographic machine to confirm the retrieval of microcalcifications. Matching the specimen radiograms, specimens with (calcified) and without (non-calcified) microcalcifications were separately picked into two different formalin-fixed bottles and then individually sent for microscopic evaluation. Pathologies were separately reported according to calcified specimens and non-calcified specimens. 


\subsection{Subsequent Surgical Excision}

Surgical excision was the first recommended procedure for all biopsy-proven malignancies. In operating the DCIS, a wide excision or partial mastectomy was used to document the complete removal of residual cancer cells. The excised specimen was routinely marked with silk stitches or oriented at the medial, lateral, superior, and inferior boundaries, so that the residual microcalcifications or cancer cells could be localized. After taking the specimen radiography, re-excision was immediately followed in cases with microcalcifications near the edge of the specimen. Another means to confirm the complete removal of residual cancer was the microscopic free-cancer margin. A breast pathological specialist reviewed all the involved cases to confirm the diagnoses of DCIS or IDC.

\subsection{Data Analysis}

Underestimation of DCIS was determined in patients with VABB-proven DCIS who were pathologically upgraded to IDC after subsequent surgery. The flowchart of the study is shown in Figure 1.

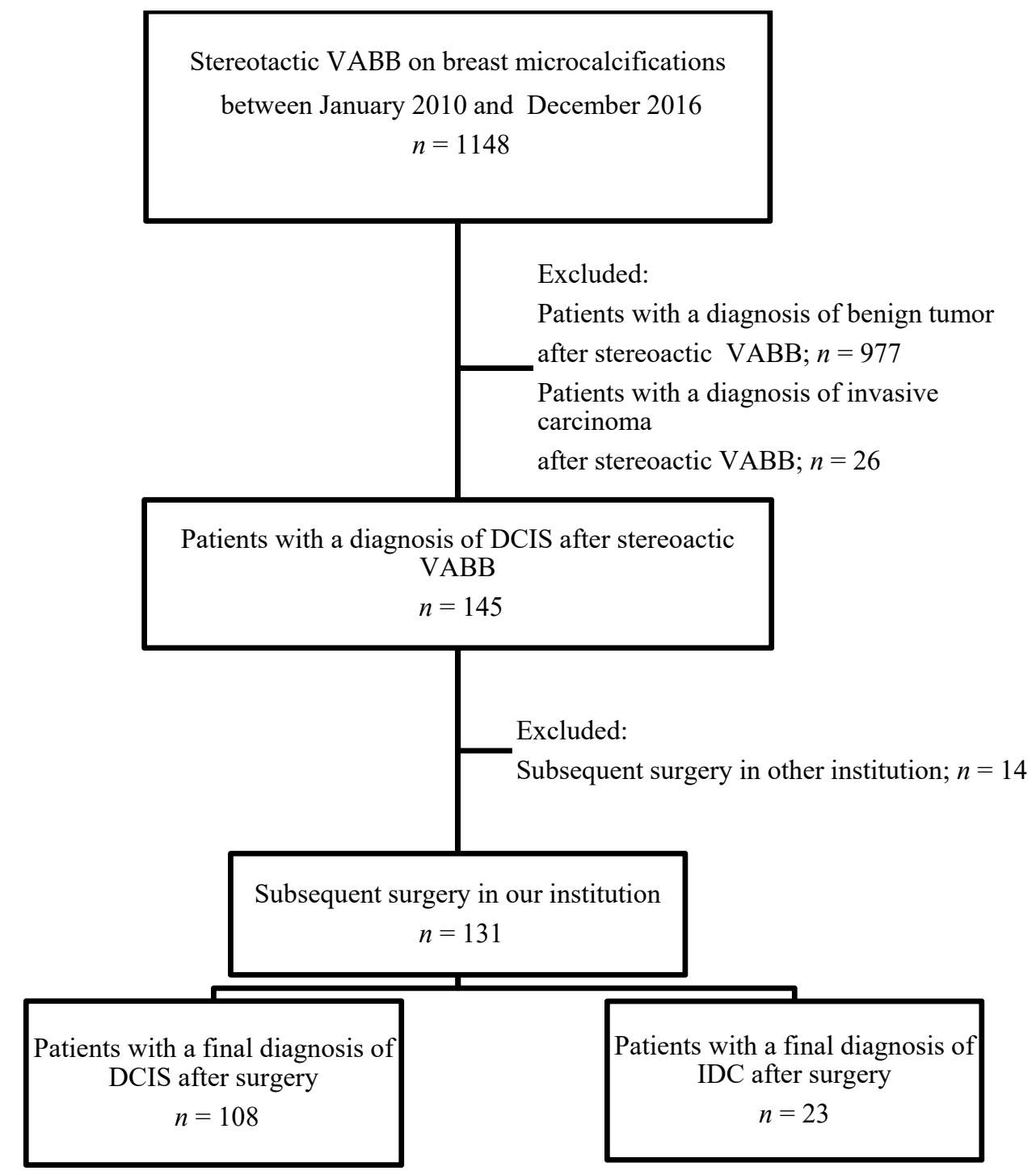

Figure 1. Flow diagram summarizing the total number of vacuum-assisted breast biopsies on suspicious microcalcifications only, and the final diagnosis after surgery. VABB: vacuum-assisted breast biopsy; DCIS: ductal carcinoma in situ; IDC: invasive ductal carcinoma. 
The variables for statistical analysis included clinical characteristics (age, side of the breast, breast cancer history), mammographic features (breast density, microcalcification extent, morphology and distribution of microcalcifications, diagnosis categories), procedural relationships (VABB needle size, percentage of calcification retrieval, diagnoses of non-calcified specimens), and histopathology (DCIS grades, status of estrogenic and progesterone receptors or HER-2).

The results of the variables were counted from the internal web of medical records. The mammographic features were standardized according to the Breast Imaging Reporting and Data System (BI-RADS) established by the American College of Radiology [16]. The breast density was divided into (1) mostly entirely fatty, (2) homogenous fibroglandular density, (3) heterogeneous fibroglandular dense breast, and (4) extremely dense breast. The microcalcifications extension indicated the longest distance either on the craniocaudal or mediolateral oblique view of the mammogram. The morphologies of microcalcifications were classified as amorphous, pleomorphic, and fine linear or branched. When the microcalcifications are polymorphous, the morphology of microcalcifications with a higher cancer probability would be recorded, in the sequence of increasing cancer probability from amorphous, pleomorphic to linear/ductal. The distributions of microcalcifications included group, regional, and liner or segmental patterns. The final diagnosis categories consisted of BI-RADS 4a, 4b, or 4c.

The gauges of the VABB needles used were either 10-G or 7-G. Microcalcification retrieval was expressed in percentages of $\geq 90 \%$ and $<90 \%$, by comparing the targeted microcalcifications on mammography before and after biopsy. Regarding pathologic results, all DCIS could be diagnosed by calcified specimens. Overall, not all non-calcified specimens could be pathologically diagnosed as DCIS. Therefore, we only analyzed the non-calcified specimens.

\subsection{Statistical Analysis}

The association between documented variables among DCIS and upgraded invasive ductal carcinoma was compared using Pearson's chi-squared test. The cutoff length for microcalcifications extent was selected to yield the highest possible Youden Index score (sensitivity + specificity -1$)$. The area under the receiver operating characteristic (ROC) curve for microcalcifications extent was calculated. A logistic regression model was used for multivariate analysis. $p$ Values $\leq 0.05$ were considered statistically significant. All statistical analyses were performed using SPSS software, version 20.0 (SPSS Inc., Chicago, IL, USA).

\section{Results}

The variables from the clinical characteristics, mammographic features, procedural relationships, and tissue biomarkers are listed in Table 1.

\subsection{Clinical Characteristics}

Of the 145 VABB cases, 131 patients received subsequent operation in our hospital, and the other 14 patients did not (Figure 1). The final surgicopathology documented 108 pure DCIS and 23 invasive cancers. All patients were female, and the median age of the patients was 52 years. Stereotactic VABB was performed in $50(51 \%)$ right breasts and $48(49 \%)$ left breasts. Three patients $(3.1 \%)$ had a history of contralateral breast cancer, and five (5.1\%) had a first-degree family history of breast cancer.

\subsection{Mammographic Features}

The breasts were predominantly classified into dense categories $(80.1 \%)$ and non-dense categories (19.9\%). The median length of microcalcifications was $12 \mathrm{~mm}$ (range, 5-66 mm). Microcalcifications appeared as amorphous in $50(38.2 \%)$, pleomorphic in $69(52.7 \%)$, and fine linear or branched in 12 $(9.2 \%)$, and the distributions were group in $96(73.3 \%)$, regional in $18(13.7 \%)$, and liner or segmental in $17(13 \%)$. Seventy-three (55.7\%) cases were classified as BI-RASDS $4 a, 31(23.7 \%)$ cases to $4 b$, and 27 (20.6\%) cases to $4 \mathrm{c}$. 
Table 1. Variables of clinical characters, mammographic features, procedural relationships and specimen biomarkers.

\begin{tabular}{|c|c|c|}
\hline \multicolumn{2}{|c|}{ Variables } & \multirow{2}{*}{$\begin{array}{c}\text { No. (\%) } \\
131(100)\end{array}$} \\
\hline Study Period & 2010-2016 & \\
\hline Age of initial diagnosis (years) & Median (IQR) & $52.0(10.0)$ \\
\hline \multirow{2}{*}{ Lesion location } & Right & $70(53.4)$ \\
\hline & Left & $61(46.6)$ \\
\hline \multirow[t]{2}{*}{ Family history of breast cancer } & Yes & $10(7.6)$ \\
\hline & No & $121(92.4)$ \\
\hline \multirow[t]{4}{*}{ Parenchymal density } & Almost entirely fat & $2(1.5)$ \\
\hline & Scattered fibroglandular & $24(18.3)$ \\
\hline & Heterogeneously dense & $84(64.1)$ \\
\hline & Extremely dense & $21(16.0)$ \\
\hline Microlcalcifications extent (mm) & Median (IQR) & $12.0(13.0)$ \\
\hline \multirow[t]{3}{*}{ Distribution of microcalcifications } & Regional & 18 (13.7) \\
\hline & Grouped & $96(73.3)$ \\
\hline & Linear or segmental & $17(13.0)$ \\
\hline \multirow[t]{3}{*}{ Morphology of microcalcifications } & Amorphous & $50(38.2)$ \\
\hline & Pleomorphic & $69(52.7)$ \\
\hline & Fine linear or branched & $12(9.2)$ \\
\hline \multirow[t]{2}{*}{ Biopsy needle gauge } & $7 \mathrm{G}$ & $27(20.6)$ \\
\hline & $10 \mathrm{G}$ & $104(79.4)$ \\
\hline \multirow[t]{2}{*}{ Microcalcification retrieval (\%) } & $<90$ & $81(61.8)$ \\
\hline & $\geq 90$ & $50(38.2)$ \\
\hline \multirow[t]{3}{*}{ BI-RADS category } & $4 \mathrm{a}$ & $73(55.7)$ \\
\hline & $4 \mathrm{~b}$ & $31(23.7)$ \\
\hline & $4 c$ & $27(20.6)$ \\
\hline \multirow[t]{3}{*}{ DCIS grade } & Low & $18(13.7)$ \\
\hline & Intermediate & $81(61.8)$ \\
\hline & High & $32(24.4)$ \\
\hline \multirow[t]{2}{*}{ Histology of non-calcified specimens } & Benign & $65(49.6)$ \\
\hline & DCIS & $66(50.4)$ \\
\hline \multirow[t]{2}{*}{ Estrogen receptor } & Negative & $28(21.4)$ \\
\hline & Positive & $103(78.6)$ \\
\hline \multirow[t]{2}{*}{ Progesterone receptor } & Negative & $35(26.7)$ \\
\hline & Positive & $96(73.3)$ \\
\hline \multirow[t]{2}{*}{ HER-2 status } & Negative & $93(71.0)$ \\
\hline & Positive & $38(29.0)$ \\
\hline
\end{tabular}

Abbreviations: IQR: interquartile range; DCIS: ductal carcinoma in situ; BI-RADS: Breast Imaging Reporting and Data System; HER-2: human epidermal growth factor receptor 2.

\subsection{Procedural Relationships}

We undertook the VABB with 7-gauge biopsy needle in 27 and 10-gauge needle in 104 patients. Among them, microcalcification retrieval was achieved in $\geq 90 \%$ in $50(38.2 \%)$ and $<90 \%$ in $81(61.8 \%)$. All calcified specimens could be diagnosed as DCIS; however, only $66(50.4 \%)$ non-calcified specimens revealed DCIS, and 65 (49.6\%) did not.

\subsection{Pathological Findings}

The DCIS grades were documented to be low in $18(13.7 \%)$, intermediate in $81(61.8 \%)$, and high in $32(24.4 \%)$. The estrogen receptors were positive in $103(78.6 \%)$ patients, while the progesterone receptors were positing in $96(73.3 \%)$ patients, and HERS-2 in $38(29 \%)$ patients.

\subsection{Univariates among DCIS and Upgraded Invasive Carcinoma}

The differences in variables among DCIS and invasive ductal carcinomas are listed in Table 2. The extent of microcalcifications, distribution of microcalcifications, percentage of microcalcification retrieval, and the histology of non-calcified specimens, estrogen receptor, progesterone receptor, and HER-2 were statistically different between DCIS and upgraded IDC. 
Table 2. Univariate analysis of the DCIS and upgraded IDC.

\begin{tabular}{|c|c|c|c|}
\hline Variables & DCIS $(n=108)$ & $\operatorname{IDC}(n=23)$ & $p$ Value \\
\hline Age & & & 0.142 \\
\hline$\leq 50$ & $46(88.5)$ & $6(11.5)$ & \\
\hline$>50$ & $62(78.5)$ & $17(21.5)$ & \\
\hline Lesion location & & & 0.744 \\
\hline Right & $57(81.4)$ & $13(18.6)$ & \\
\hline Left & $51(83.6)$ & $10(16.4)$ & \\
\hline Family history of breast cancer & & & 0.208 \\
\hline Yes & $10(100.0)$ & 0 & \\
\hline No & $98(81.0)$ & $23(19.0)$ & \\
\hline Parenchymal density & & & 0.420 \\
\hline Almost entirely fat & $1(50.0)$ & $1(50.0)$ & \\
\hline Scattered fibroglandular & $19(79.2)$ & $5(20.8)$ & \\
\hline Heterogeneously dense & $72(85.7)$ & $12(14.3)$ & \\
\hline Extremely dense & $16(76.2)$ & $5(23.8)$ & \\
\hline Microcalcifications extent (mm) & & & 0.002 \\
\hline$<11.5$ & $58(93.5)$ & $4(6.5)$ & \\
\hline$\geq 11.5$ & $50(72.5)$ & $19(27.5)$ & \\
\hline Distribution of microcalcifications & & & 0.021 \\
\hline Regional & $11(61.1)$ & $7(38.9)$ & \\
\hline Grouped & $84(87.5)$ & $12(12.5)$ & \\
\hline Linear or segmental & $13(76.5)$ & $4(23.5)$ & \\
\hline Morphology of microcalcifications & & & 0.195 \\
\hline Amorphous & $45(90.0)$ & $5(10.0)$ & \\
\hline Pleomorphic & $54(78.3)$ & $15(21.7)$ & \\
\hline Fine linear or branched & $9(75.0)$ & $3(25.0)$ & \\
\hline Biopsy needle gauge & & & 0.783 \\
\hline $7 \mathrm{G}$ & $23(85.2)$ & $4(14.8)$ & \\
\hline $10 \mathrm{G}$ & $85(81.7)$ & $19(18.3)$ & \\
\hline Microcalcification retrieval (\%) & & & 0.006 \\
\hline$<90$ & $61(75.3)$ & $20(24.7)$ & \\
\hline$\geq 90$ & $47(94.0)$ & $3(6.0)$ & \\
\hline BI-RADS category & & & 0.345 \\
\hline $4 \mathrm{a}$ & $63(86.3)$ & $10(13.7)$ & \\
\hline $4 b$ & $25(80.6)$ & $6(19.4)$ & \\
\hline $4 c$ & $20(74.1)$ & $7(25.9)$ & \\
\hline DCIS grade & & & 0.221 \\
\hline Low & $17(94.4)$ & $1(5.6)$ & \\
\hline Intermediate & $67(82.7)$ & $14(17.3)$ & \\
\hline High & $24(75.0)$ & $8(25.0)$ & \\
\hline Histology of non-calcified specimens & & & $<0.0001$ \\
\hline Benign & $63(96.9)$ & $2(3.1)$ & \\
\hline DCIS & $45(68.2)$ & $21(31.8)$ & \\
\hline Estrogen receptor & & & 0.009 \\
\hline Negative & $18(64.3)$ & $10(35.7)$ & \\
\hline Positive & $90(87.4)$ & $13(12.6)$ & \\
\hline Progesterone receptor & & & 0.045 \\
\hline Negative & $25(71.4)$ & $10(28.6)$ & \\
\hline Positive & $83(86.5)$ & $13(13.5)$ & \\
\hline HER-2 status & & & 0.001 \\
\hline Negative & $83(89.2)$ & $10(10.8)$ & \\
\hline Positive & $25(65.8)$ & $13(34.2)$ & \\
\hline
\end{tabular}

Abbreviations: DCIS: ductal carcinoma in situ; IDC: invasive ductal carcinoma; BI-RADS: Breast Imaging Reporting and Data System; HER-2: human epidermal growth factor receptor 2.

The optimal cut off of microcalcifications extent was $11.5 \mathrm{~mm}$. The DCIS upgraded to IDC was $6.5 \%$ when the microcalcifications extent was $<11.5 \mathrm{~mm}$, which was statistically significant, to $27.5 \%$ with an extent $\geq 11.5 \mathrm{~mm}$. Among the distributions of microcalcifications, the group pattern of 
microcalcifications had the lowest upgrade percentage (12.5\%) as compared to regional or linear or segmental. When the microcalcification retrieval was $\geq 90 \%$, the upgrade rate decreased to $6 \%$ from $24.7 \%$ to $>90 \%$. For the non-calcified specimens, whether they contained DCIS or not, the upgrade rates to IDC were $31.8 \%$ for those with DCIS and 3.1\% for those without DCIS. The negative estrogen receptor, negative progesterone receptor, and positive Her-2 had higher upgrade rates.

Using multivariate logistic regression, only the non-calcified specimen was statistically significant for predicting the upgrade of DCIS to invasive carcinoma. The odds ratio was 1 to 21.492 (95\% CI 0.969-116.649, <0.001) (Table 3).

Table 3. Multivariate logistic regression in predicting DCIS underestimation.

\begin{tabular}{|c|c|c|c|}
\hline \multirow{2}{*}{ Variables } & \multicolumn{3}{|c|}{ Multivariate } \\
\hline & Odds Ratio & $95 \% \mathrm{CI}$ & $p$ Value \\
\hline \multicolumn{4}{|c|}{ Microcalcifications extent (mm) } \\
\hline$<11.5$ & 1 & & \\
\hline$\geq 11.5$ & 1.734 & $0.290-10.373$ & 0.546 \\
\hline \multicolumn{4}{|c|}{ Distribution of microcalcification } \\
\hline Grouped & 1 & & \\
\hline Regional & 1.788 & $0.365-8.775$ & 0.474 \\
\hline Linear or segmental & 0.560 & $0.098-3.215$ & 0.515 \\
\hline \multicolumn{4}{|c|}{ Microcalcification retrieval (\%) } \\
\hline$<90$ & 3.452 & $0.577-20.637$ & 0.175 \\
\hline$\geq 90$ & 1 & & \\
\hline \multicolumn{4}{|c|}{ Histology of non-calcified specimens } \\
\hline Benign & 1 & & \\
\hline DCIS & 21.492 & $3.960-116.649$ & $<0.001$ \\
\hline \multicolumn{4}{|l|}{ Estrogen receptor } \\
\hline Negative & 10.267 & $0.520-202.855$ & 0.126 \\
\hline Positive & 1 & & \\
\hline \multicolumn{4}{|l|}{ Progesterone receptor } \\
\hline Negative & 0.117 & $0.006-2.408$ & 0.165 \\
\hline Positive & 1 & & \\
\hline \multicolumn{4}{|l|}{ HER-2 status } \\
\hline Negative & 1 & & \\
\hline Positive & 2.606 & 0.649-10.466 & 0.177 \\
\hline
\end{tabular}

Abbreviations: DCIS: ductal carcinoma in situ; CI: confidence interval; HER-2: human epidermal growth factor receptor 2 .

\section{Discussion}

DCIS, also known as intraductal carcinoma, indicates the presence of abnormal cells confined within the milk duct, which is distinguishable from invasive ductal carcinoma. Most of them are asymptomatic or without palpable masses, which often only present as microcalcifications on mammograms. Although such in situ carcinoma refers to the "preinvasive carcinoma" status, excision needs to be performed in which $20 \%$ to $30 \%$ of those who do not receive treatment developed invasive carcinoma [17]. The operative methods, either with conservative or total mastectomy, are the same in DCIS or IDC; however, knowledge of predicting the underestimation of VABB proved that DCIS facilitates preoperative planning. Basically, it is not advised to undergo sentinel lymph node biopsy with pure DCIS. Obviation of the supplementary performance of sentinel lymph node biopsy will provide benefits including shortening of the operative time, avoiding unnecessary exposure to radiation dose, or minimizing the potential complications of lymph node resection.

In our series, $17.55 \%$ of $131 \mathrm{VABB}-$ diagnosed DCIS were microscopically revealed to be invasive components after subsequent surgery. Preoperative mammograms were used for the review. About $80 \%$ of breasts were classified as dense and $20 \%$ as non-dense. The extent and distribution of microcalcifications were statistically significant between pure DCIS and upgraded IDC. The optimal cutoff size was found to be $11.5 \mathrm{~mm}$. When the extent was smaller than $11.5 \mathrm{~mm}$, the DCIS 
underestimation was significantly low $(6.5 \%)$. Nevertheless, other studies have suggested that $30 \mathrm{~mm}$ or $40 \mathrm{~mm}$ might have a higher probability of underestimation $[18,19]$. It is understood that a trend for increased size was suspected among the underestimated cases, but this is still controversial, as statistical significance and insignificance have never been reported $[20,21]$. The cut off DCIS underestimation was hard to define, and should preferably be dependent on the sample collection.

Microcalcifications in group pattern (defined as more than five microcalcifications gathered within a $2 \mathrm{~cm}^{2}$ area on the mammogram) were the most widely classified in our series, accounting for $73.3 \%$. Among the distribution patterns, the regional pattern had the highest upgrade percentage to IDC $(38.9 \%)$, followed by the linear or segmental pattern $(23.5 \%)$ and group pattern $(12.5 \%)$. This could be explained by larger territories having a higher chance of underestimation.

The tissue amount obtained by biopsy procedures is an important factor for correct microscopic diagnosis. Because of the advanced development of spring-loaded to vacuum-assisted needles, it has become easier to obtain larger tissues for examination. Complete or mostly complete removal of targeted microcalcifications has become common. Achievement depends on the extent of microcalcification. However, complete removal of targeted microcalcifications has not been standardized for procedure termination. In contrast, biopsy-induced bleeding is practically considered, and post-biopsy hematoma often obscures any residual microcalcifications on the postprocedural mammogram. Thus, we simply assessed nearly $(\geq 90 \%)$ and below nearly $(<90 \%)$ complete microcalcification removal. Our results support the nearly complete removal of microcalcifications, as this had a lower underestimation rate than the below nearly complete removal ( $6 \%$ versus $24.7 \%)$. Of course, nearly complete microcalcification removal was exclusive to a small extent of grouped microcalcifications. In certain cases of a larger size, an increased number of core specimens would obtain more microcalcifications, which might lower the underestimation rate [22,23]. Unfortunately, the number of core specimens could not guarantee the percentage of microcalcification retrieval, and the number of samples was dependent on the operator's decision.

There were no statistically significant differences in DCIS underestimation between the sizes of biopsy needles, which included 7-gauge and 10-gauge needles in our series. However, specimens with or without microcalcification would almost certainly be obtained regardless of the biopsy needle used, 7-gauge or 10-gauge, and they would receive their individual diagnoses [24]. The calcified specimens were more valuable to cancer diagnosis than non-calcified specimens $[25,26]$. Cheung et al. reported remarkable differences in diagnostic accuracies (91.54\% versus $69.49 \%$ ) after comparing calcified specimens to non-calcified specimens in individual cases [25]. This is in agreement with Margolin et al., who demonstrated that cores with calcification on specimen radiographs were more likely to enable a final diagnosis of malignancy than were cores without calcification (84\% versus $71 \%$ ) [26]. In this analysis, we found that the non-calcified specimens were predictive of DCIS underestimation. There was only a $3.1 \%$ upgrade rate for non-calcified specimens diagnosed as non-cancerous diagnoses, and a $31.8 \%$ upgrade rate in those with DCIS diagnoses ( $p$ value $<0.0001)$. This result was also supported by multivariate logistic regression. To our knowledge, such results have not been published previously. We explained the abnormal cancer cells confined within the ductules of the breast that were less extensive to the neighboring breast tissues as compared to IDC. Conversely, the non-calcified specimen revealed with DCIS indicates larger cancer involvement near the sites of biopsy.

\section{Conclusions}

In cases of DCIS manifesting with microcalcifications only on mammograms, the small extent of microcalcifications, grouped microcalcifications distribution, nearly complete microcalcification removal, and non-calcified specimens without DCIS had lower DCIS underestimation. The non-calcified specimens were highly predictive of DCIS underestimation. Specimens without DCIS had a low upgrade rate to invasive cancers.

Author Contributions: Conceptualization, C.-C.Y. and Y.-C.C.; methodology, S.-C.C.; software, C.-C.Y.; validation, C.-C.Y., S.-H.U. and Y.-C.C.; formal analysis, S.-C.C.; investigation, C.-C.Y.; resources, Y.-C.C.; data curation, 
S.-H.U.; writing—original draft preparation, Y.-C.C.; writing-review and editing, C.-C.Y. All authors have read and agreed to the published version of the manuscript.

Funding: This research received no external funding.

Ethics Approval: The study was approved by the Chang Gung Medical Foundation Institutional Review Board (IRB No: 202000419B0). The ethics committees waived the need for written informed consent because no intervention was involved and the retrospective analysis of clinical data.

Conflicts of Interest: The authors declare no conflict of interest.

\section{References}

1. Sankatsing, V.D.V.; van Ravesteyn, N.T.; Heijnsdijk, E.A.M.; Looman, C.W.N.; van Luijt, P.A.; Fracheboud, J.; de Heeten, G.J.; Broeders, M.J.M.; de Koning, H.J. The effect of population-based mammography screening in Dutch municipalities on breast cancer mortality 20 years of follow-up. Int. J. Cancer 2017, 141, 671-677. [CrossRef]

2. Bruening, W.; Fontanarosa, J.; Tipton, K.; Treadwell, J.R.; Launders, J.; Schoelles, K. Systematic Review: Comparative Effectiveness of Core-Needle and Open Surgical Biopsy to Diagnose Breast Lesions. Ann. Intern. Med. 2010, 152, 238. [CrossRef] [PubMed]

3. Kettritz, U.; Rotter, K.; Schreer, I.; Murauer, M.; Schulz-Wendtland, R.; Peter, D.; Heywang-Köbrunner, S. Stereotactic vacuum-assisted breast biopsy (VB) in 2874 patients: A multicenter study. Cancer 2004, 100, 245-251. [CrossRef] [PubMed]

4. Huang, M.L.; Adrada, B.E.; Candelaria, R.; Thames, D.; Dawson, D.; Yang, W.T. Stereotactic Breast Biopsy: Pitfalls and Pearls. Tech. Vasc. Interv. Radiol. 2014, 17, 32-39. [CrossRef] [PubMed]

5. Kunju, L.P.; Kleer, C.G. Significance of flat epithelial atypia on mammotome core needle biopsy: Should it be excised? Hum. Pathol. 2007, 38, 35-41. [CrossRef]

6. Chivukula, M.; Bhargava, R.; Tseng, G.C.; Dabbs, D.J. Clinicopathologic Implications of "Flat Epithelial Atypia" in Core Needle Biopsy Specimens of the Breast. Am. J. Clin. Pathol. 2009, 131, 802-808. [CrossRef]

7. Senetta, R.; Campanino, P.P.; Mariscotti, G.; Garberoglio, S.; Daniele, L.; Pennecchi, F.; Macri, L.; Bosco, M.; Gandini, G.; Sapino, A. Columnar cell lesions associated with breast calcifications on vacuum-assisted core biopsies: Clinical, radiographic, and histological correlations. Mod. Pathol. 2009, 22, 762-769. [CrossRef]

8. Eby, P.R.; Ochsner, J.E.; DeMartini, W.B.; Allison, K.H.; Peacock, S.; Lehman, C.D. Frequency and Upgrade Rates of Atypical Ductal Hyperplasia Diagnosed at Stereotactic Vacuum-Assisted Breast Biopsy: 9-Versus 11-Gauge. Am. J. Roentgenol. 2009, 192, 229-234. [CrossRef]

9. Sneige, N.; Lim, S.C.; Whitman, G.J.; Krishnamurthy, S.; Sahin, A.A.; Smith, T.L.; Selling, C.B. Atypical ductal hyperplasia diagnosis by directional vacuum-assisted stereotactic biopsy of breast microcalcifications. Considerations for surgical excision. Am. J. Clin. Pathol. 2003, 119, 248-253. [CrossRef]

10. Ingegnoli, A.; D’Aloia, C.; Frattaruolo, A.; Pallavera, L.; Martella, E.; Crisi, G.; Zompatori, M. Flat Epithelial Atypia and Atypical Ductal Hyperplasia: Carcinoma Underestimation Rate. Breast J. 2010, 16, 55-59. [CrossRef]

11. Degnim, A.C.; Visscher, D.W.; Berman, H.K.; Frost, M.H.; Sellers, T.A.; Vierkant, R.A.; Maloney, S.D.; Pankratz, V.S.; De Groen, P.C.; Lingle, W.L.; et al. Stratification of Breast Cancer Risk in Women With Atypia: A Mayo Cohort Study. J. Clin. Oncol. 2007, 25, 2671-2677. [CrossRef] [PubMed]

12. Becker, A.K.; Gordon, P.B.; Harrison, D.A.; Hassell, P.R.; Hayes, M.M.; Van Niekerk, D.; Wilson, C.M. Flat Ductal Intraepithelial Neoplasia 1A Diagnosed at Stereotactic Core Needle Biopsy: Is Excisional Biopsy Indicated? Am. J. Roentgenol. 2013, 200, 682-688. [CrossRef] [PubMed]

13. Dialani, V.; Venkataraman, S.; Frieling, G.; Schnitt, S.J.; Mehta, T.S. Does Isolated Flat Epithelial Atypia on Vacuum-assisted Breast Core Biopsy Require Surgical Excision? Breast J. 2014, 20, 606-614. [CrossRef] [PubMed]

14. Brennan, M.; Turner, R.M.; Ciatto, S.; Marinovich, M.L.; French, J.R.; Macaskill, P.; Houssami, N. Ductal Carcinoma in Situ at Core-Needle Biopsy: Meta-Analysis of Underestimation and Predictors of Invasive Breast Cancer. Radiology 2011, 260, 119-128. [CrossRef]

15. Lyman, G.H.; Somerfield, M.R.; Bosserman, L.D.; Perkins, C.L.; Weaver, D.L.; Giuliano, A.E. Sentinel lymph node biopsy for patients with early stage breast cancer: American Society of Clinical Oncology Clinical Practice guideline update. J. Clin. Oncol. 2017, 35, 561-564. [CrossRef] 
16. Burnside, E.S.; Ochsner, J.E.; Fowler, K.J.; Fine, J.P.; Salkowski, L.R.; Rubin, D.L.; Sisney, G.A. Use of microcalcification descriptors in BI-RADS 4th edition to stratify risk of malignancy. Radiology 2007, 242, 388-395. [CrossRef]

17. Correa, C.; McGale, P.; Taylor, C.; Wang, Y.; Clarke, M.; Davies, C.; Peto, R.; Bijker, N.; Solin, L.; Darby, S. Overview of the randomized trials of radiotherapy in ductal carcinoma in situ of the breast. J. Natl. Cancer Inst. Monogr. 2010, 41, 162-177.

18. Brem, R.F.; Schoonjans, J.M.; Goodman, S.N.; Nolten, A.; Askin, F.B.; Gatewood, O.M.B. Nonpalpable Breast Cancer: Percutaneous Diagnosis with 11- and 8-gauge Stereotactic Vacuum-assisted Biopsy Devices1. Radiology 2001, 219, 793-796. [CrossRef]

19. Orsaria, P.; Granai, A.V.; Venditti, D.; Petrella, G.; Buonomo, O.C. Investigational Paradigms in Downscoring and Upscoring DCIS: Surgical Management Review. Int. J. Surg. Oncol. 2012, 2012, 1-10. [CrossRef]

20. Philpotts, L.E.; Lee, C.H.; Horvath, L.J.; Lange, R.C.; Carter, D.; Tocino, I. Underestimation of Breast Cancer with II-Gauge Vacuum Suction Biopsy. Am. J. Roentgenol. 2000, 175, 1047-1050. [CrossRef]

21. Lourenco, A.P.; Mainiero, M.B.; Lazarus, E.; Giri, D.; Schepps, B. Stereotactic Breast Biopsy: Comparison of Histologic Underestimation Rates with 11- and 9-Gauge Vacuum-Assisted Breast Biopsy. Am. J. Roentgenol. 2007, 189, W275-W279. [CrossRef] [PubMed]

22. Jackman, R.J.; Burbank, F.; Parker, S.H.; Evans, W.P.; Lechner, M.C.; Richardson, T.R.; Smid, A.A.; Borofsky, H.B.; Lee, C.H.; Goldstein, H.M.; et al. Stereotactic Breast Biopsy of Nonpalpable Lesions: Determinants of Ductal Carcinoma in Situ Underestimation Rates. Radiology 2001, 218, 497-502. [CrossRef] [PubMed]

23. Liberman, L.; Dershaw, D.D.; Rosen, P.P.; Morris, E.A.; Abramson, A.F.; Borgen, P.I. Percutaneous removal of malignant mammographic lesions at stereo- tactic vacuum-assisted biopsy. Radiology 1998, 206, 711-715. [CrossRef] [PubMed]

24. Huang, P.C.; Lin, Y.C.; Cheng, H.Y.; Juan, Y.H.; Lin, G.G.; Cheung, Y.C. Performance of Stereotactic Vacuum-Assisted Biopsy on Breast Microcalci cations: Comparison of 7-gauge and 10-gauge Biopsy Needles. J. Radiol. Sci. 2020, 45, 25-31.

25. Cheung, Y.-C.; Juan, Y.-H.; Ueng, S.-H.; Lo, Y.-F.; Huang, P.-C.; Lin, Y.-C.; Chen, S.-C. Assessment of Breast Specimens With or Without Calcifications in Diagnosing Malignant and Atypia for Mammographic Breast Microcalcifications without Mass: A STARD-compliant diagnostic accuracy article. Medicine 2015, 94, e1832. [CrossRef]

26. Margolin, F.R.; Kaufman, L.; Jacobs, R.P.; Denny, S.R.; Schrumpf, J.D. Stereotactic Core Breast Biopsy of Malignant Calcifications: Diagnostic Yield of Cores with and Cores without Calcifications on Specimen Radiographs1. Radiology 2004, 233, 251-254. [CrossRef] 